\title{
Catalogação de metadados: descrição de metadados de negócio a partir dos princípios e objetivos bibliográficos
}

\author{
Mariana Baptista Brandt \\ http://orcid.org/0000-0001-8119-7527
}

\section{Silvana Aparecida Borsetti Gregório VidottiII} http://orcid.org/0000-0002-4216-0374

\section{Plácida Leopoldina Ventura Amorim da Costa Santos ${ }^{I I I}$}

Zaira Regina Zafalon ${ }^{I V}$

http://orcid.org/0000-0002-4467-2138

${ }^{I}$ Universidade Estadual Paulista, Marília, SP, Brasil.

Doutoranda em Ciência da Informação.

II Universidade Estadual Paulista, Marília, SP, Brasil.

Docente do Departamento de Ciência da Informação.

${ }^{\text {III }}$ Universidade Estadual Paulista, Marília, SP, Brasil.

Docente do Programa de Pós-Graduação em Ciência da Informação.

${ }^{I V}$ Universidade Federal de São Carlos, São Carlos, SP, Brasil.

Docente do Programa de Pós-Graduação em Ciência da Informação.

http://dx.doi.org/10.1590/1981-5344/2930

O presente artigo analisa os princípios e os objetivos bibliográficos postulados ao longo do tempo nas discussões sobre catalogação pela perspectiva da gestão de metadados de negócio. Discute as definições de metadados e metadados de negócio e aborda as atividades de descrição bibliográfica e de gestão de metadados. Nos objetivos e nos princípios bibliográficos são encontradas diretrizes para a atividade de descrição, fundamental para a realização de gestão de metadados de negócio.

Palavras-chave: Metadado de negócio. Gestão de metadados. Catalogação. Princípios bibliográficos. Objetivos bibliográficos. 


\section{Metadata cataloging: business metadata description based on the bibliographic principles and objectives}

The present article analyses the bibliographic principles and objectives postulated throughout the years in the discussions about cataloging seen from the business metadata management. It discusses the definitions of metadata and business metadata and approaches the activities of bibliographic description and metadata management. In the bibliographic objectives and principles guidelines are found for the activity of description, which is fundamental for the business metadata management.

Keywords: Business metadata. Metadata management. Cataloging. Bibliographic principles. Bibliographic objectives.

Recebido em 19.09.2016 Aceito em 30.07.2019

\section{Introdução}

Com o crescimento exponencial da produção de informação, a multiplicação dos seus meios de armazenamento nos diversos suportes e plataformas existentes, e principalmente, com a migração para o meio digital, a discussão sobre metadados ganhou destaque nas áreas de informação e tecnologia. Muito tem sido abordado sobre a importância deste elemento e suas características, utilidades e aplicações nos sistemas de informação, com destaque para seu uso no ambiente web.

O termo metadado pode ser definido de várias maneiras conforme destaca Gilliland (2008, p. 1, tradução nossa): "[...] termo entendido de diferentes formas pelas diversas comunidades profissionais que planejam, descrevem, criam, preservam e usam sistemas e recursos de informação". Foulonneau e Riley (2008, p. 6, tradução nossa) definem metadados como "[...]informação estruturada sobre um recurso digital e suas propriedades". Taylor (2004) também apresenta várias definições de metadado, a começar pela genérica "dados sobre dados", e afirma que o que todas as definições têm em comum é a noção de metadado como informação estruturada que descreve atributos de recursos informacionais com os propósitos de identificação, descoberta e gerenciamento.

Os metadados são elementos de descrição utilizados na representação bibliográfica desde o surgimento dos primeiros 
instrumentos de controle bibliográfico, como as bibliografias e os catálogos. Lancaster (2004), na 2. edição do livro Indexação e resumos: teoria e prática, faz uma nota sobre terminologia e o que ele chama de reinvenção da roda, ou seja, uso de novos termos para conceitos antigos e, muitas vezes, já consagrados em uma área do conhecimento:

Exemplo óbvio é 'metadados'. O Oxford English Dictionary registra 1968 como o ano do aparecimento dessa palavra. Na época foi usada para designar dados que descreviam conjuntos de dados (numéricos ou estatísticos). Desde então tornou-se praticamente um substituto para 'descrição bibliográfica', denominação perfeitamente razoável, com a qual convivíamos há muitos e muitos anos e que é aceita em normas internacionais. (LANCASTER, 2004, p. xii)

No artigo Metadata: cataloguing by any other name..., Feldman e Milstead (1999) também levantam essa questão e afirmam que metadado é um conceito já familiar aos profissionais da informação que foi trazido ao mundo pela era eletrônica.

Pode-se dizer então que, apesar dos novos usos e significados atribuídos, o laço entre os conceitos de metadado e de descrição bibliográfica é discutido na Ciência da Informação há vários anos. Pretende-se com este artigo iniciar uma nova discussão, trazendo para a Ciência da Informação o conceito de metadados de negócio. O presente trabalho trata-se de um ensaio para construção de referencial teórico de pesquisa e busca encontrar nos princípios e nos objetivos bibliográficos, diretrizes para a descrição de metadados de negócio.

\section{Metadados de negócio}

As informações de uma instituição estão geralmente armazenadas em sistemas de informação, automatizados ou não, e fazem parte - como insumo ou produto - dos processos de trabalho da instituição. Essas informações precisam ser mapeadas, registradas e gerenciadas para que sejam utilizadas de forma uniforme e consistente pela instituição. Uma das formas de se realizar a gestão dessa informação institucional é com o gerenciamento de metadados. Segundo Sherman (2006, p. 50, tradução nossa): "Gestão de metadados é o ingrediente secreto que possibilita o sucesso e a sustentabilidade da gestão da performance corporativa, governança e outras iniciativas que alimentam dados de negócio." O autor fala sobre a importância da gestão de metadados, mas ressalta a confusão conceitual existente entre os termos: frequentemente, os metadados técnicos são confundidos com os metadados de negócio, e é o segundo que possibilita alavancar a gestão corporativa.

Inmon, Fryman e O'Neil (2007) definem metadados de negócio como o contexto de negócio por trás dos dados e afirmam que servem para ajudar os gestores de negócio, ou seja, usuários não técnicos, no entendimento do dado. Os autores explicam que: 
A exploração devida dos metadados de negócio tanto por especialistas em TI quanto por gestores de negócio pode revolucionar o uso da tecnologia, tornando-a facilitadora do conhecimento empresarial que sempre deveria ter sido. A tecnologia pode ajudar em como os metadados de negócio podem permitir que o negócio seja conduzido em vários níveis, desde a facilitação da comunicação e verdadeiro entendimento para fornecer background informacional para que decisões apropriadas possam ser tomadas. (INMON; FRYMAN; O'NEAL, 2007, p.6, tradução nossa)

Sherman (2006, p. 50, tradução nossa) compartilha deste entendimento e se refere à metadados de negócio como "[...] o que o gestor do negócio precisa saber sobre o que seus dados representam". Ao contrário do termo genérico "metadado", a categoria específica dos metadados de negócio parece possuir uma definição mais consensual entre os autores. O entendimento do termo como o tipo de metadado que contextualiza dados do negócio possibilitando aos gestores e outros atores da área de negócio um entendimento unificado do dado tem sido aceito e utilizado desde os anos 1990 nas áreas de Informática e de Inteligência de negócios.

A gestão de metadados, citada por Sherman (2006) como a chave para a gestão do conhecimento empresarial, pressupõe a identificação dos metadados de negócio. Uma vez identificados nos processos de trabalho da instituição, os metadados de negócio devem ser gerenciados. A partir dessa identificação, quais procedimentos devem ser realizados para a gestão efetiva dos metadados de negócio? A análise da gestão de metadados deve possibilitar a determinação desses procedimentos.

\subsection{Gestão de metadados de negócio}

A gestão de metadados de negócio pressupõe inicialmente sua identificação nos processos de trabalho e seu registro, pois os metadados de negócio encontram-se dispersos pelos documentos e sistemas utilizados no processo e, muitas vezes, estão apenas na cabeça dos gestores e de outros atores envolvidos com o processo de trabalho:

Metadados de negócios existem desde que o homem montou 0 primeiro negócio. Então todos os metadados de negócio existiram na cabeça do dono do negócio e seus executores. Ao longo do tempo, os metadados de negócio foram gravados nos instrumentos escritos disponíveis a cada época (formulários, documentos, imagens, e-mails, planilhas, sistemas, etc). Apesar disso, ainda há alguns metadados de negócio que existem apenas na cabeça de quem executa o negócio. (INMON; FRYMAN; O'NEAL, 2007, p.6, tradução nossa).

Dessa forma, entende-se que a primeira tarefa para a gestão de metadados de negócio é a sua identificação. A partir da análise das informações do negócio, deve ser realizada a extração desses metadados. Para isso, é importante que os processos de trabalho estejam mapeados. 
Cada atividade do processo deve ser analisada com foco nas informações necessárias para sua realização e também nas informações que possam vir a ser produzidas no decorrer da atividade. Essas informações estão muitas vezes em documentos, planilhas, sistemas, e é aí que se encontram os metadados de negócio. A tarefa do analista de informação é, então, a partir da análise dos itens informacionais, identificar os metadados de negócio que estão dispersos pelos processos, muitas vezes de forma não-estruturada, e, então registrá-los, para que fiquem documentados.

O registro é a etapa que transforma os metadados de negócio antes existentes de forma abstrata, dispersa e não estruturada em entidades manifestadas e, assim, passíveis de gerenciamento. Além disso, o registro é importante e deve ser realizado pois permite que os metadados de negócio sejam:

- definidos: uma vez identificados e registrados, os metadados de negócio precisam de uma definição: deve ser atribuído o entendimento da área de negócio sobre o que cada metadado significa. A criação dessas definições deve também permitir o início da criação de um glossário de negócios da instituição e servir como instrumento de controle terminológico. Uma vez que as informações são produzidas e consumidas pelas diversas áreas de uma instituição, é importante que todos que utilizam o metadado de negócio o entendam da mesma forma, com o mesmo conceito;

- descritos: os metadados de negócio podem ser vistos como entidades que possuem vários atributos. A definição do metadado é um desses atributos. Acredita-se que outros atributos deverão ser eleitos para compor a descrição do metadado de negócio, e para isso, eles precisam estar registrados;

- buscados: em qualquer empresa ou organização, há vários macro processos nas diferentes áreas (recursos humanos, contabilidade, comunicação, processos meio e finalísticos da instituição etc). Para cada um desses macro processos há diferentes processos de trabalho, que vão desde os procedimentos para efetuar o pagamento dos funcionários até os de manutenção predial, passando por diversos outros processos. Metadados de negócio podem ser encontrado em cada um desses processos. Sem o devido registro de cada um desses metadados, não seria possível encontrá-los novamente, nem acessá-los para nenhum fim, e, consequentemente, não poderiam ser gerenciados;

- reutilizados: é importante que os metadados de uma instituição sejam reutilizados para evitar retrabalhos e 
criação de sistemas com informações conflitantes. O registro dos metadados de negócio possibilita que eles sejam usados com consistência nos diferentes sistemas e processos da instituição.

Foram identificadas, então, três atividades básicas necessárias para a gestão de metadados: identificação, registro e descrição. O registro permite que o metadado de negócio seja definido, descrito, buscado e reutilizado. A seção a seguir trata da atividade de descrição de metadados de negócio, pois acredita-se que, como na atividade de catalogação descritiva realizada no contexto das bibliotecas, os metadados de negócio também podem possuir itens de descrição (atributos) e serem descritos por meio desses atributos, ou seja, catalogados.

\subsection{Descrição de metadados e catalogação descritiva}

A informação é organizada por meio de sua descrição e o que é descrito pode ser chamado de entidade bibliográfica. Svenonius (2000) afirma que o universo bibliográfico é dinâmico e, portanto, qualquer modelo deve ser extensível de modo a permitir a representação de entidades ainda não especificadas. Entendendo que os metadados de negócio podem ser vistos como entidades a serem descritas, assim como as entidades bibliográficas, busca-se aqui traçar um comparativo entre as atividades.

As atividades de descrição bibliográfica e descrição de metadados de negócio possuem algumas semelhanças, e a primeira que pode ser apontada é a necessidade do registro. Só é possível fazer a descrição de uma informação se ela está registrada. Por exemplo, no caso dos registros bibliográficos, o item físico (manifestação) é o registro de uma obra (conteúdo intelectual), que é descrita com base em seus atributos, por exemplo: título, autor, editora e data de publicação. Da mesma forma, metadados de negócio existem de forma não estruturada, dispersos nos vários documentos, processos e sistemas da instituição, e, para que sejam descritos, devem ser registrados e compilados de forma sistemática.

Os atributos a serem descritos para os itens bibliográficos já foram pré-definidos por meio dos instrumentos de representação, como códigos de catalogação e padrões de metadados estabelecidos e utilizados para a descrição. Já para os metadados de negócio, é preciso identificar quais são esses atributos, ou seja, o que descrever sobre os metadados de negócio, e como descrever essas informações.

Definido isso, a atividade que deve ser realizada para a gestão de metadados de negócio pode ser comparada com a atividade de catalogação bibliográfica: catalogar um livro, por exemplo, consiste em identificá-lo e descrever seus atributos para que possa ser encontrado, selecionado, utilizado etc. Layne (1989, p. 190, tradução nossa) destaca três funções da catalogação descritiva: 
[...] fornecer acesso ao item bibliográfico, fornecer um arranjo útil dos registros nos catálogos e descrever um item de modo que 0 usuário possa identificar se é exatamente o que ele procurava ou se é potencialmente útil, apesar de desconhecido anteriormente.

Ou seja, para que seja possível realizar a gestão de uma coleção de livros, cada um desses itens deve estar representado (registrado e descrito) em um repositório (catálogo). O registro bibliográfico contém a descrição do livro: seus atributos intelectuais (título, autor, assunto etc) e físicos (número de páginas, dimensões etc).

As atividades necessárias para a gestão de metadados são similares. Pode-se comparar os metadados de negócio a livros que precisam ser descritos. Deve-se encontrar elementos que permitam identificá-lo como único em uma coleção e descrever esses elementos (atributos) de forma coerente com as descrições de atributos de outros metadados - ou seja, utilizando as mesmas regras. A diferença é que no caso de registros bibliográficos, a maioria das informações que devem ser descritas encontram-se no próprio objeto da descrição. Poucos são os elementos, quando existem, que devem ser buscados fora do item descrito: às vezes não é possível identificar o ano de publicação ou o número de páginas (caso de objetos informacionais digitais); mas a grande maioria dos elementos está no próprio item, considerando os objetos informacionais tradicionais de catalogação bibliográfica (livros, revistas, artigos, etc).

Já para os metadados de negócio, não há nenhum atributo intrínseco. Tudo que se queira saber a respeito do metadado de negócio deve ser extraído de outras fontes de informação: pessoas, sistemas, documentos etc. O metadado de negócio nasce com apenas um nome atribuído, como "número do voo", "ano da compra" ou "prazo de entrega", e assim é registrado. Sua descrição deve ser feita a partir de elementos externos a ele, ao contrário da descrição de registros bibliográficos. Porém, em ambos os casos, os elementos são inerentes e complementares e se consolidam na descrição.

A catalogação de itens bibliográficos é uma atividade que vem sendo realizada e analisada há muito tempo e, por isso, acredita-se que esse conhecimento pode ser utilizado para guiar a atividade de descrição de metadados, no sentido de identificação de atributos e regras para descrição. Pretende-se analisar os princípios e objetivos da catalogação para se obter um norte para a descrição de metadados de negócio.

\subsection{Princípios bibliográficos}

Os princípios bibliográficos são diretrizes gerais para a criação de regras de descrição. Segundo a International Federation of Library Associations and Institutions (IFLA, 2009, p. 2) os princípios "[...] destinam-se a orientar o desenvolvimento de códigos de catalogação [...] podem também ser aplicados a bibliografias e outros ficheiros (arquivos) de dados criados por bibliotecas, arquivos, museus e outras 
comunidades". Svenonius (2000) explica os princípios bibliográficos partindo de dois princípios gerais:

- Princípio da razoabilidade: coincide com o cânone da imparcialidade, de Ranganathan, e diz que as bases para cada decisão devem ser defensáveis e não arbitrárias;

- Princípio da parcimônia: também segundo Ranganathan, cânone da parcimônia, e diz que quando há diferentes formas de se atingir um objetivo, deve-se escolher a mais econômica.

Acredita-se que esses dois princípios gerais possam ser utilizados, também, para a descrição de metadados de negócio por se tratarem de diretrizes genéricas e, portanto, aplicáveis ao contexto da gestão de metadados.

Svenonious (2000) destaca, do mesmo modo, os objetivos mais específicos, entre os que foram reconhecidos pela literatura em catalogação anglo-americana, voltados para a elaboração de linguagens de descrição bibliográfica (SVENONIUS, 2000, p. 68, tradução nossa):

- Princípio da conveniência do usuário: as decisões tomadas sobre a elaboração das descrições deve ter os usuários em mente;

-Subprincípio do uso comum: vocabulários normalizados usados na descrição devem estar de acordo com a maioria dos usuários;

- Princípio da representação: a descrição deve ser baseada em como a entidade de informação se auto descreve;

oSubprincípio da exatidão: descrições devem ser fiéis a entidade descrita;

- Princípio da suficiência e necessidade: descrições devem ser suficientes para atingir os objetivos declarados e não devem incluir elementos não necessários para esse propósito;

-Subprincípio da significância: descrições devem conter apenas os elementos significativos bibliograficamente;

- Princípio da padronização: descrições devem ser padronizadas, na extensão e nível que for possível;

- Princípio da integração: descrições para todos os tipos de materiais devem ser baseados em um conjunto comum de regras, na extensão em que isso for possível.

Segundo Svenonius (2000, p. 69), há discussões e questionamentos sobre esses princípios e alguns contêm falhas ou conflitos, como o princípio do uso comum, apresentado por Cutter como vago e não científico; o princípio da exatidão, que por si só não garante a recuperação 
efetiva da informação; e o princípio da padronização, que, se excessivo, pode conflitar com o princípio da conveniência do usuário, entre outros exemplos fornecidos pela autora (SVENONIUS, 2000, p. 69 et seq., tradução nossa). Apesar disso, o uso desses princípios como diretrizes, ainda deve ser considerado na elaboração de um sistema de gestão de informação atual:

Os princípios desejados podem nem sempre admitir critérios fáceis e pontuais (sharp), mas deve-se lembrar que critérios são instrumentos para facilitar a aplicação dos princípios, não para substituí-los. Abandonar princípios salutares por causa da dificuldade de definir critérios pontuais é o mesmo que abandonar uma bússola numa região selvagem por causa dos obstáculos encontrados no caminho indicado. (LUBETZKY, 1953, p. 129, tradução nossa).

Dentre os princípios elencados, acredita-se que os seguintes possam ser utilizados como diretrizes na descrição de metadados de negócio: princípio da conveniência do usuário e subprincípio do uso comum, princípio da suficiência e necessidade e subprincípio da significância e princípio da padronização.

O princípio da conveniência do usuário pode ser aplicado no contexto dos metadados de negócio no qual os gestores e executores do negócio são os usuários da informação. Dessa forma, as decisões sobre a descrição dos metadados devem ser focadas no pessoal envolvido no negócio. Os vocabulários utilizados, principalmente na definição dos metadados de negócio, devem estar de acordo com o entendimento da maioria dos atores envolvidos no processo de trabalho. Esse princípio está de acordo com o entendimento de Sherman (2006) sobre a gestão de metadados de negócio:

A maioria dos metadados de negócio não é registrada em ferramentas ou precisa de uma tradução da linguagem técnica para a linguagem do negócio. O problema começa porque muito dos metadados de negócio contidos nos requisitos de negócio usados para a construção de data warehouse e projetos de relatórios, mas quando a TI implementa uma solução tecnológica, o que sobra do metadado de negócio é uma intepretação técnica armazenada nas ferramentas. A linguagem do negócio se perde. O principal desafio para os metadados de negócio é retomar o que foi perdido e traduzir para o metadado da ferramenta (SHERMAN, 2006, p. 50, tradução nossa).

Já o princípio da suficiência e necessidade e seu subprincípio da significância corroboram com o princípio geral da parcimônia: não é necessário descrever o que não colabora para o cumprimento de um objetivo. A descrição de metadados de negócio deve ser suficiente para se atingir os objetivos de seu gerenciamento, e aqui já é possível prever que deve haver objetivos variados nas diversas instituições. O princípio da padronização é aplicável e deve ser utilizado sempre que se deseja realizar qualquer tipo de trabalho de organização de informação, dado que 
registros de informações de forma padronizada facilitam a recuperação e a elaboração de relatórios gerenciais.

Já os demais princípios não podem ser aplicados como diretrizes para a descrição de metadados de negócio. O princípio da representação e seu subprincípio da exatidão referem-se à descrição da entidade bibliográfica de forma exata, com a transcrição das informações como se encontram na própria entidade, sem alterações. Garante-se a exatidão pela prescrição da fonte de informação para descrição e pela transcrição dos elementos conforme aparecem na fonte: "[...] a característica mais importante do livro, para fins de catalogação, é o fato de que ele vem com uma etiqueta de identificação proeminente, em forma de folha de rosto" (LUBETSKY, 2001, p. 118, tradução nossa). Para os metadados de negócio, conforme discutido anteriormente, os elementos para descrição não estão na própria entidade e devem ser buscados em fontes externas. Assim, esses princípios, nesse contexto, não fazem sentido. O que poderia ser aproveitado deste princípio para a descrição de metadados de negócio seria a recomendação de indicação das fontes de informação para a busca dos elementos de descrição. Também não se identifica um paralelo quanto ao princípio da integração, que está relacionado à descrição uniforme para os diferentes tipos de materiais, o que não se aplica ao contexto de metadados de negócio.

Em suma, os princípios que podem auxiliar na gestão de metadados de negócio encontram-se no quadro a seguir:

Quadro 1 - Princípios bibliográficos aplicáveis à gestão de metadados de negócio

\begin{tabular}{|c|c|}
\hline Princípios & $\begin{array}{c}\text { Aplicação na gestão de metadados de } \\
\text { negócio }\end{array}$ \\
\hline Princípio da razoabilidade & $\mathrm{x}$ \\
\hline Princípio da parcimônia & $\mathrm{x}$ \\
\hline $\begin{array}{c}\text { Princípio da conveniência do usuário } \\
\text { Subprincípio do uso comum }\end{array}$ & $\mathrm{x}$ \\
\hline $\begin{array}{c}\text { Princípio da representação } \\
\text { Subprincípio da exatidão }\end{array}$ & $\mathrm{x}$ \\
\hline $\begin{array}{c}\text { Princípio da suficiência e necessidade } \\
\text { Subprincípio da significância }\end{array}$ & $\mathrm{x}$ \\
\hline Princípio da padronização & Não se aplica \\
\hline Princípio da integração & \\
\hline
\end{tabular}

Fonte: produção das autoras

Assim, após análise, nota-se que a maioria dos princípios bibliográficos pode ser aplicada à gestão de metadados de negócio, reafirmando sua importância para a gestão da informação.

\subsection{Objetivos bibliográficos}


Os objetivos bibliográficos ou objetivos do catálogo explicam para que a atividade de descrição bibliográfica (catalogação) é feita. Além disso, os objetivos servem como guias para o desenvolvimento de sistemas de informação:

O primeiro passo no planejamento de um sistema bibliográfico é a definição de seus objetivos. Todas as outras características - como entidades, atributos e relacionamentos reconhecidos pelo sistema e as regras usadas para construir descrições bibliográficas - são garantidos se e somente se eles contribuem para a realização de um ou mais objetivos. (SVENONIUS, 2000, p. 15, tradução nossa).

Os objetivos bibliográficos vêm sendo apontados desde a época de Panizzi, no século XIX, quando ele afirmou que o catálogo deve unir itens semelhantes e diferenciá-los de outros. Segundo Lubetzky (1953, p. 114), os objetivos implícitos nas regras de entrada (determinar se a biblioteca possui um livro específico e mostrar quais as obras de um determinado autor) já eram defendidos por Panizzi e foram seguidos nas regras de catalogação anglo-americanas.

Segundo Svenonius (2000), Cutter foi o primeiro a explicitar os objetivos de um sistema bibliográfico, em 1876. Eram eles:

1) encontrar: permitir que a pessoa encontre um livro em que seu autor, título ou assunto é conhecido;

2) dispor: mostrar o que a biblioteca possui, de acordo com algum critério (autor, assunto);

3) escolher: ajudar na escolha de um livro.

Esses objetivos foram discutidos posteriormente por Lubetzky e revisados na Conferência dos Princípios de Catalogação, em Paris, em 1961, e ficaram conhecidos como Princípios de Paris (SEVENONIUS, 2000). Estes não incluíram o objetivo "escolher" e nem abordaram a busca por assuntos. Em 1997, a IFLA retoma a discussão e atualiza os objetivos para:

1) encontrar entidades que correspondem ao critério de busca do usuário;

2) identificar uma entidade, confirmar que a entidade descrita no registro corresponde a que foi buscada ou distingui-la de outras com características similares;

3) selecionar a entidade mais apropriada às necessidades do usuário;

4) adquirir ou obter acesso à entidade descrita (empréstimo, compra, acesso eletrônico etc).

Svenonius (2000, p. 19) acrescenta o objetivo de navegar aos propostos pela IFLA em 1997. A autora afirma que os quatro objetivos não são suficientes e justifica com dois argumentos. O primeiro está relacionado com o comportamento do usuário e sua necessidade de 
navegar pelo catálogo para encontrar o que precisa e o segundo analisa os códigos tradicionais para descrição bibliográfica, afirmando que um dos objetivos das regras e definições de relacionamentos nos códigos bibliográficos é facilitar a navegação.

Em 2009, a IFLA faz uma nova publicação da declaração de princípios internacionais de catalogação e aceita a proposta de Svenonius, acrescentando o objetivo de navegar. Assim, como versão atual da IFLA para os objetivos bibliográficos, apresentam-se:

- encontrar recursos bibliográficos numa coleção como resultado de uma pesquisa, utilizando atributos e relações entre recursos;

- identificar um recurso bibliográfico ou agente;

- selecionar um recurso bibliográfico que seja apropriado às necessidades do utilizador;

- adquirir ou obter acesso a um item descrito;

- navegar num catálogo ou para além dele.

Considerando-se os objetivos bibliográficos propostos nas várias épocas, pode-se analisar quais deles poderiam ser aplicados na descrição de metadados de negócio. Para isso, cada objetivo será analisado individualmente, com foco na gestão de metadados de negócio.

Primeiramente o objetivo encontrar, sempre presente nas propostas de objetivos bibliográficos. Pode-se entender que encontrar é o objetivo básico de qualquer sistema de informação: as informações são registradas para que possam ser encontradas ou recuperadas posteriormente. Dessa forma, o objetivo "encontrar" é também um dos objetivos da atividade de registro de metadados de negócio, conforme dito anteriormente.

O próximo objetivo, entre os elencados por Cutter, é o de dispor (collocating), que ressalta a necessidade de que itens sejam dispostos segundo algum critério, formando um conjunto de recursos bibliográficos que possuem alguma similaridade predeterminada pelo usuário, ou seja, que tenham o mesmo autor, ou o mesmo assunto, etc. Acredita-se que, definidos os atributos dos metadados de negócio, também seja importante que eles possam ser recuperados por algum critério específico - atributo $x$ ou y. O objetivo de dispor, nesse contexto, seria uma forma de deixar claro que o sistema de recuperação deve permitir que a informação seja recuperada por qualquer critério predefinido, trazendo como resultado os conjuntos de entidades que possuem o mesmo atributo como critério.

O objetivo escolher, proposto por Cutter está relacionado com o objetivo selecionar, da IFLA, e prevê que seja permitido ao usuário escolher/selecionar a entidade bibliográfica mais pertinente às suas necessidades de informação. A relação com a gestão de metadados de negócio pode não ficar muito clara para este objetivo, mas, considerandose os gestores e os executores de negócios e os envolvidos no fornecimento de soluções tecnológicas para as áreas de negócio (técnicos 
em informática) como os usuários da entidade descrita (metadados de negócio), pode-se criar uma relação com o objetivo de forma a escolher/selecionar o metadado de negócio mais apropriado para: descrever uma informação do processo, utilizar em um processo de trabalho, selecionar em um banco de dados, incluir em um relatório gerencial, entre outras "necessidades do usuário". De forma semelhante, pode-se fazer um paralelo também para o objetivo de identificar: entre os vários metadados de negócio já mapeados de uma instituição, o usuário (gestor do processo, gestor de informação ou gestor de TI) deve identificar com precisão a que metadado de negócio se refere uma informação do processo, tabela de sistema e outros. Assim, adaptando o objetivo identificar para a gestão de metadados de negócio apresenta-se: "confirmar que a entidade (metadado de negócio) descrita no registro (localizada no sistema, processo, repositório) corresponde a que foi buscada (em repositório de gestão de metadados ou em documentos de trabalho ou sistemas de informação) ou distingui-la de outras com características similares".

O objetivo adquirir/obter está muito relacionado ao acesso ou consumo do conteúdo de informação da entidade. A analogia que pode ser feita é no sentido de que os metadados de negócio armazenados em repositórios poderiam ser obtidos (acesso a informações sobre o metadado de negócio) e reutilizados em outros processos ou sistemas de informação.

Por fim, o objetivo navegar, que visa permitir que o usuário percorra o catálogo de forma a reconhecer um item que precisa pode também ser útil quando se considera que o usuário é, por exemplo, o desenvolvedor de sistemas que busca o metadado correto para uma nova ferramenta de automação, ou o analista que modela as informações de um processo de trabalho e precisa identificar se um determinado metadado de negócio já foi mapeado no repositório da instituição. A navegação por um repositório/catálogo de metadados de negócio seria importante para a realização desta tarefa.

A partir desta discussão acerca dos objetivos bibliográficos, a aplicação dos mesmos para a gestão de metadados de negócio pode ser resumida no quadro a seguir:

Quadro 2: Objetivos bibliográficos aplicáveis à gestão de metadados de negócio

\begin{tabular}{|c|c|}
\hline Objetivo & Aplicação para gestão de metadados de negócio \\
\hline Encontrar & $\mathrm{x}$ \\
\hline Dispor & $\mathrm{x}$ \\
\hline Escolher / Selecionar & $\mathrm{x}$ \\
\hline Identificar & $\mathrm{x}$ \\
\hline Adquirir / obter & $\mathrm{x}$ \\
\hline Navegar & $\mathrm{x}$ \\
\hline
\end{tabular}

Fonte: produção das autoras 
Como pode ser observado, todos os objetivos bibliográficos fazem sentido para a gestão de metadados de negócio. Tal fato deve ocorrer devido às semelhanças significantes que as atividades de descrição bibliográfica e descrição de metadados de negócio possuem.

\subsection{Descrição de metadados de negócio}

A partir da análise dos princípios e objetivos bibliográficos foi possível identificar aqueles que podem auxiliar na definição do processo de descrição de metadados de negócio. Acredita-se que a tentativa de trazer a atividade de descrição de metadados de negócio para o contexto da catalogação tradicional apresente condições para auxiliar a definição dos atributos a serem descritos.

Considerando o objetivo "encontrar", o atributo de identificação do próprio metadado de negócio já pode ser mencionado: cada metadado de negócio precisa ser nomeado de forma a não se confundir com outros. Escolher, selecionar e identificar pressupõem uma definição para cada metadado de negócio, ou seja, aspectos terminológicos são importantes e aí entra a diretriz postulada no princípio da conveniência do usuário/uso comum sobre a elaboração da descrição na linguagem do usuário.

O objetivo "dispor" traz à discussão os critérios pelos quais os metadados de negócio podem ser recuperados de modo a formar arranjos. Esses critérios são novos atributos do metadado de negócio e para identificá-los deve-se considerar a seguinte questão:

- Além de sua definição, quais outros atributos podem contribuir para a efetiva gestão de metadados de negócio de uma instituição?

O objetivo "navegação" também pressupõe a identificação desses novos atributos e essa tarefa deve levar em conta, além dos objetivos bibliográficos identificados, os objetivos da instituição. Ao promover a gestão de metadados de negócio é importante questionar:

- Para que é feita a descrição de metadados de negócio?

- Quais são as informações necessárias sobre os metadados de negócio?

- Quais atributos são desejáveis para a informação da instituição?

- Há regras relacionadas às informações institucionais?

Essas questões devem ser respondidas considerando-se o princípio da suficiência e necessidade e o subprincípio da significância, para que apenas atributos realmente necessários sejam mapeados e descritos. Do contrário, a gestão de metadados de negócio pode se tornar muito custosa para a instituição e o custo é sempre um argumento forte para se deixar de fazer gestão de informação, conforme afirma Svenonius (2001) 
ao discorrer sobre argumentos contrários à implementação dos objetivos bibliográficos para o desenvolvimento de sistemas de informação. Isso pode acontecer principalmente em instituições que não visam lucro, como órgãos governamentais, em que a informação não é vista de fato como um ativo da instituição. O princípio da padronização também é importante quando se pergunta sobre regras relacionadas às informações, já que muitas relacionam-se ao uso de padrões.

Outra forma de se identificar atributos para a descrição de metadados de negócio é pela análise de normas, regulamentos e políticas de informação da instituição, quando houver. Nelas costumam-se encontrar requisitos para a gestão da informação na instituição e esses requisitos podem ser alcançados por meio de atributos da informação. Como comentado anteriormente, os atributos para a descrição de metadados de negócio devem seguir os objetivos da instituição e, por isso, podem não ser iguais para todas as instituições, uma vez que os objetivos variam. Contudo, é provável que um corpo mínimo comum de atributos seja necessário a qualquer instituição que realize a gestão de metadados de negócio, assim como um nível mínimo de descrição bibliográfica comum é necessário a todas as bibliotecas. Acredita-se que os objetivos bibliográficos possam fornecer este corpo mínimo de atributos para descrição de metadados de negócio.

\section{Conclusão}

A atividade de catalogação ou descrição bibliográfica é realizada pelos profissionais da informação há vários séculos. Há pelo menos 150 anos, desde a época da Royal Commission on Panizzi's Rules, de 1849, catalogadores se reúnem para discutir, aprender e aperfeiçoar esta tarefa, discutindo seus objetivos, princípios e diretrizes internacionais. Este artigo buscou encontrar nesse corpo de conhecimento, fundamentos para uma nova vertente de descrição: a gestão de metadados de negócio.

Metadados de negócio são elementos importantes para a gestão da informação e trazem informações que refletem o conhecimento da instituição, permitindo alavancar os objetivos estratégicos, a performance da gestão corporativa e a gestão do conhecimento na empresa.

A partir da análise feita neste trabalho observou-se que a maioria dos princípios e objetivos bibliográficos pode ser utilizada para guiar as atividades de gestão de metadados de negócio, especialmente em sua descrição. Sugere-se que há forte aderência entre as áreas de descrição bibliográfica e descrição de metadados de negócio. Pretende-se realizar pesquisa futura para definir atributos necessários para a descrição de metadados de negócio com base nos objetivos e princípios identificados neste trabalho.

\section{Referências}


FOULONNEAU, M; RILEY, J. Metadata for digital resources:

implementation, systems design and interoperability. Oxford: Chandos, 2008.

GILLIAND, Anne J. Setting the stage. In: BACA, M (ed). Introduction to metadata. 2008. Online Edition, version 3.0. Disponível em:

http://www.getty.edu/research/publications/electronic publications/intro metadata/setting.pdf. Acesso em: 23 mar. 2016.

INMON, W. H., O'NEIL, B., \& FRYMAN, L. Business metadata: Capturing enterprise knowledge. Boston: Morgan Kaufmann, 2008.

INTERNATIONAL FEDERATION OF LIBRARY ASSOCIATIONS AND INSTITUTIONS. Declaração de princípios internacionais de catalogação. 2009. Disponível em: http://www.ifla.org/publications/statement-ofinternational-cataloguing-principles. Acesso em: 30 mar. 2016.

LANCASTER, F. W. Indexação e resumos: teoria e prática. 2.ed. Brasília: Briquet de Lemos, 2004.

LAYNE, S. S. Integration and the objectives of the catalog. In:

SVENONIUS, E. The Conceptual foundations of descriptive cataloging. San Diego: Academic Press, 1989.

LUBETZKY, S. Cataloging rules and principles: a critique of the ALA rules for entry and a proposed design for their revision, 1953 In: LUBETZKY, S. ; SVENONIUS, E.; MCGARRY. D. Seymour Lubetzky : writings on the classical art of cataloging. Englewood, Colo.: Libraries Unlimited, 2001.

MILSTEAD, J.; FELDMAN, S. Metadata: Cataloging by any other name... Online, Medford, v. 23, n. 1, p. 24-31, Jan 1999.

https://pdfs.semanticscholar.org/bc7e/38fb1e6b8375df020d28a88331644 cab2681.pdf. Acesso em: 30 mar. 2016.

SHERMAN, R. Align Metadata and Business Initiatives. DM Review, New York, v. 16, n. 1, p. 50, Jan. 2006.

SVENONIUS, E. The Intellectual foundation of information organization. Cambridge: MIT Press, 2000.

TAYLOR, A. G. The organization of information. New York : Libraries Unlimited, 2004. 